\title{
Avaliação dos níveis de aglutininas antileptospira em cães de caça na Paraíba, Brasil*
}

\section{Evaluation of anti-leptospire agglutinines leves in hunt dogs in the Paraíba, Brazil}

\author{
Clebert José Alves, ${ }^{* *}$ Inácio José Clementino, ${ }^{* * * *}$ Alan Glayboon de Freitas Oliveira, ${ }^{* * *}$ Theonys Diógenes Freitas, ${ }^{* *}$ \\ Silvio Arruda Vasconcellos, ${ }^{* * *}$ Zenaide Macedo Morais ${ }^{* * * * *}$
}

\begin{abstract}
Resumo
Dentre os animais domésticos, em nível urbano, os cães representam a principal fonte de infecção da leptospirose humana, pois vivem em contato direto com o homem e uma vez infectados podem eliminar leptospiras vivas através da urina durante meses, mesmo sem apresentar sinais clínicos da doença. Particularmente, os cães de caça constituem animais de companhia que são utilizados por adeptos da atividade esportiva de caça à procura de espécies silvestres no meio rural, sendo esta uma prática comum em várias regiões do Brasil. O presente trabalho teve como objetivo pesquisar a presença de aglutininas antileptospira em cães de caça no estado da Paraíba. Foram utilizados na pesquisa 190 cães de caça provenientes de 11 cidades paraibanas, sendo $172(90,53 \%)$ machos e 18 (9,74\%) fêmeas com idades variando de seis meses a 15 anos, criados em sua maioria presos e as principais espécies caçadas (informes dos proprietários) eram em ordem decrescente de freqüência: tatu-verdadeiro, tatu-peba, tejo, tacaca, tamanduá e raposa. Os soros sangüíneos de cães de caça foram processados pela técnica de Soroaglutinação Microscópica (SAM) no Laboratório de Doenças Transmissíveis/CSTR/UFPB. Das 190 amostras analisadas, $17(8,95 \%)$ foram reagentes para sete sorotipos de Leptospira patogênicos, com destaque para autumnalis, bratislava e australis, com títulos variando de 100 a 1.600.
\end{abstract}

Palavras-chave: cães de caça, aglutininas antileptospiras, sorotipos.

\begin{abstract}
Among the domestic animals, in urban level, the dogs represent the main source of human leptospire infection for they often live in company of man. Dogs tend to eliminate living leptospira throug their urine during some months without showing any clinical sign. Hunt dogs constitute company animals that they are used in search of by followers of the sporting activity of hunt wild species in the rural way, being this, a common practice in several areas of Brasil. This research aims to evaluate the antileptospira agglutinines levels in hunt dogs in state of Paraíba, Brasil. Were collected 190 blood samples the dogs, proceeding from 11 cities, being $172(90,53 \%)$ males and 18 (9,74\%) females with ages varying of 6 months to 15 years. The blood samples were processed according to the Microscopic Agglutination Technique (MAT) in the Contagious Diseases Laboratory - CSTR/ Campus VII/UFPB. After resultads it was observed the prevalence of $8,95 \%$ of the samples with prominence for the following serovars: autumnalis, bratislava e australis.
\end{abstract}

Keywords: hunt dogs, agglutination, anti-leptospire.

\section{Introdução}

A leptospirose é uma doença zoonótica de distribuição mundial, ocorrendo em várias espécies de animais domésticos e silvestres (Kalin et al., 1999), cujo agente etiológico é um espiroqueta pertencente à ordem Spirochaetales, família Leptospiraceae, gênero Leptospira constituído pelas espécies $L$. interrogans, L. borgpetersenii, L. weilli, L. noguchii, $L$. santarosai, L. kirchneri e L. feini.
A ocorrência de leptospirose é variável em diferentes partes do mundo, podendo-se observar tanto as formas esporádicas quanto a endêmica. Os surtos se reproduzem por exposição à água contaminada com urina ou tecidos provenientes de animais infectados (Turner, 1967), particularmente nas ocasiões em que ocorrem elevados índices de precipitações pluviométricas e nas regiões em que o solo apresenta reação neutra ou levemente alcalina, associando-se ainda à vari-

\footnotetext{
*Trabalho vinculado ao programa PIBIC/CNPq da UFPB/CSTR.

** Professor Doutor da Universidade Federal de Campina Grande/CSTR/DMV/CAMPUS de Patos-PB. CEP:58700-194. Cxpostal: 64. clebertja@uol.com.br

*** Médicos-veterinários autônomos

**** Professor titular da FMVZ/Universidade de São Paulo

***** Universidade Federal de Campina Grande, mestrando em Med. Vet. clementinoij@yahoo.com.br

****** Universidade de São Paulo - técnica de laboratório de Zoonoses Bacterianas - bióloga
} 
edade de espécies hospedeiras que facilitam a cadeia de eventos necessários para a transmissão da leptospirose.

Uma vez em contato com a pele lesada ou a mucosa do hospedeiro susceptível, as leptospiras ganham a corrente circulatória e inicia-se a fase de multiplicação do agente no sangue e em diversos órgãos afins como: fígado, baço, rins; este é o período de leptospiremia (Faine, 1982; Guimarães et al., 1983) e tem uma duração média de quatro a cinco dias, raramente superando sete dias.

Quando o animal consegue superar a fase aguda, o seu sistema imune reage, produzindo anticorpos que antagonizam as leptospiras, presentes nos diversos humores, tecidos e órgãos, fazendo com que as mesmas persistam apenas em algumas áreas do organismo em que os anticorpos ocorrem em baixos níveis como é o caso da luz dos túbulos renais (Vasconcellos, 1987).

A leptospirose canina pode sofrer influência sazonal. Verão e outono são os períodos em que se encontra maior número de cães com títulos de anticorpos (Yasuda et al., 1980).

Dentre os vários sorotipos que constituem o complexo Leptospira interrogans, os sorotipos canícola e icterohaemorrhagiae são considerados os mais importantes para a espécie canina (Girio, 1993), como também indicam vários inquéritos sorológicos recentemente realizados no Brasil (Avila et al., 1998; Lilenbaum et al., 2000). No entanto, trabalhos realizados em outros países têm evidenciado a crescente introdução de outros sorotipos causando leptospirose em cães como pomona, grippotyphosa, bratislava e autumnalis (Brown et al., 1996; Kalin et al., 1999; Ribotta et al., 2000; Prescott et al., 2002).

O sorotipo canícola determina um quadro clínico de nefrite e gastroenterite, podendo em alguns casos, a infecção assintomática. Quando ocorre evolução das alterações renais, o animal apresenta uremia, insuficiência renal, enterite hemorrágica, coma e morte em uma alta porcentagem de casos. O sorotipo icterohaemorrhagiae causa nos cães, na maioria das vezes, a síndrome ictero-hemorrágico, semelhante ao quadro clínico da doença de Weil no homem. Geralmente aguda e se manifesta clinicamente por: hipertermia, prostração, hemorragias, especialmente nos pulmões e apareIho digestivo, que podem levar a insuficiência hepática (Gírio, 1993; Hagiwara, 1993).

Dentre os animais domésticos, em nível urbano, a principal fonte de infecção da leptospirose humana são os cães, pois estes animais vivem em contato direto com o homem e podem eliminar leptospiras vivas através da urina durante meses, mesmo sem apresentar nenhum sinal clínico (Avila et al., 1998). Neste particular, devem ser considerados os cães de caça, que são utilizados por seus proprietários em atividades de caça no meio rural; este fato constitui uma prática comum, em que várias pessoas adotam esta atividade como rotina de lazer, na qual se deslocam para ambientes silvestres pouco habitados à procura de animais silvestres, tendo como companhia cães.

Os cães representam um importante elo de transmissão da leptospirose, visto que aparentemente sadios, portam leptospiras e as eliminam ao meio ambiente propício à disseminação para outras espécies, inclusive ao homem (Bauab et al., 1993). Vários sorotipos foram isolados na espécie ca- nina, encontrando-se na literatura citações de australis, bataviae, autumnalis, hebdomadis e menadencis (Kolochine et al., 1957). O sorotipo pyrogenes foi isolado na Argentina (Aguirre, 1969). O sorotipo grippotyphosa foi isolado de dois cães com leptospirose na Geórgia (Brown et al., 1996).

No Brasil e na maioria dos outros países, o isolamento de sorotipos em cães limita-se a canícola e icterohaemorrhagiae (Azevedo e Santos, 1945). No Brasil, Castro et al. (1962) observaram, pela primeira vez, cães reagentes para outros sorotipos - pomona, tarassovi, hyos, sejroe, australis e bataviae.

O isolamento de leptospiras exerce um papel de relevância indiscutível no controle da enfermidade, pois permite o conhecimento exato dos diferentes sorotipos que existem em um determinado lugar.

Deste modo, o presente trabalho teve como objetivo pesquisar a presença de aglutininas anti-leptospira em soro sangüíneo de cães de caça localizados no meio urbano e rural de diferentes cidades do estado da Paraíba.

\section{Material e métodos}

ANIMAIS: Foram utilizados nesta pesquisa cães de caça, originários de diferentes bairros da cidade de Patos, e outras dez cidades paraibanas como mostra a Tabela 2. Estes animais são criados e fazem parte de uma rotina ou prática de lazer dos proprietários que criam estes animais para conjuntamente participarem destas atividades no finais de semana.

AMOSTRAS DE SANGUE: Foram colhidas 190 amostras de sangue de cães de caça, provenientes de diferentes bairros da cidade de Patos, bem como de animais pertencentes a ou residentes em outras cidades paraibanas (Tabela 2). No momento da colheita foi aplicado um questionário para obterse informações sobre os principais animais caçados ou capturados e a região onde costumavam caçar. Desse modo, vimos que os proprietários dos cães de caça deslocavam-se para outras cidades e até para outros estados, o que nos incentivou a coletar amostras nessas cidades também.

O sangue foi obtido por veno-punção cefálica, utilizando-se seringas descartáveis e tomando-se todos os cuidados de assepsia. Em seguida, o sangue foi transferido para frascos estéreis (tubos de ensaio), identificados e enviados para o Laboratório de Doenças Transmissíveis do CSTR/UFPB, aonde fez-se o dessoramento (centrífuga a 3.000 rpm por $15 \mathrm{mi}-$ nutos) e o congelamento das amostras a $-20^{\circ} \mathrm{C}$.

AMOSTRAS DE SORO: Foram submetidas para determinação dos níveis de aglutininas antileptospira nos animais trabalhados. Sua execução seguiu metodologia da microtécnica descrita por Galton et al. (1965), com tempo e temperatura de incubação, respectivamente de três horas e 28 a $30^{\circ} \mathrm{C}$ positivos. Foram utilizados na reação de Soroaglutinação Microscópica (SAM), antígenos vivos (sorotipos especificados) originários do Laboratório de Zoonoses Bacterianas da Faculdade de Medicina Veterinária e Zootecnia da Universidade de São Paulo, contendo 23 sorovares (australis, bratislava, autumnalis, butembo, castellonis, bataviae, canicola, whitcombi, cynopteri, grippotyphosa, hebdomadis, copenhageni, icterohaemorrhagiae, panama, pomona, pyrogenes, hardjo, wolffi, shermani, tarassovi, andamana, 
patoc e sentot). O critério adotado para o soro ser considerado como reagente foi de $50 \%$ de leptospiras agluti-nadas por campo microscópico no aumento de 100 vezes. O sorotipo registrado foi o que apresentou maior título, na eventualidade do maior título ser apresentado para dois ou mais sorotipos, o animal foi excluído da análise.

Tratamento estatatístico: Foi realizado utilizando-se o programa Epi-info 2000.

\section{Resultados}

A Tabela 1 apresenta os resultados dos 190 soros processados, sendo que destes 17 (8,95\%) foram reagentes positivos para um ou mais sorotipos de Leptospira. Os sorotipos encontrados foram autumnalis (42,31\%), bratislava (15,38\%), australis (11,54\%), butembo, grippotyphosa e icterohaemorrhagiae $(7,69 \%)$, e andamana e wolffi (3,85\%); com títulos variando de 100 a 1.600 , sendo 11 (42,31\%) com títulos 100, e 6 (23,08\%), 4 (15,38\%), 1 (3,85\%) com títulos iguais a 200,400 e 800 , e 1.600 respectivamente.

A Tabela 2 menciona as 11 cidades onde foram colhidas as amostras. Destas, apenas duas não apresentaram animais reagentes para leptospirose. Esta tabela mostra também as cidades que apresentaram a maior porcentagem de amostras positivas e os sorotipos reagentes.

A Tabela 3 demonstra os resultados dos exames dos animais segundo a faixa etária e a natureza dos resultados. Dos animais usados na pesquisa, $20 \%$ tinham menos de dois anos e desses, 5,26\% eram reagentes positivos para leptospirose; 59,47\% tinham dois a quatro anos de idade com $9,78 \%$ reagentes e $20,53 \%$ tinham mais de quatro anos, sendo $10,26 \%$ deles reagentes. Em relação ao total de positivos, 64,71\% tinham dois a quatro anos de idade. A análise estatística pelo programa Epi-info não revelou diferenças entre as variáveis estudadas

A Tabela 4 apresenta os resultados segundo o número de vezes que os animais eram utilizados nas atividades esportivas de caça no meio silvestre e a natureza dos resultados. De acordo com os dados da tabela, viu-se que $36,32 \%$ dos cães eram levados para caçar até três vezes por mês, sendo $8,7 \%$ deles reagentes positivos para leptospirose; $42,63 \%$ caçavam quatro a seis vezes, com $7,41 \%$ reagentes e, $21,05 \%$ caçavam mais de sete vezes com $12,5 \%$ de reagentes. Em relação ao total de positivos, os animais que eram levados para caçar até três e de quatro a seis vezes ao mês tiveram $70,58 \%$ de positividade, portanto (35,29\%) cada grupo. A análise estatística pelo programa Epi-info não revelou diferenças significativas entre as variáveis estudadas.
Verificou-se que $90,53 \%$ dos animais pesquisados eram machos e $85,26 \%$ do total eram criados exclusivamente presos. Apenas uma fêmea e quatro animais criados soltos foram reagentes para leptospirose. Os principais animais silvestres caçados ou capturados (informes dos proprietários) eram em ordem decrescente de freqüência: tatu-verdadeiro (Dasypus novemcinctus), peba (Eupharactus sexinctus), tejo (Tupinabis merianal), tamanduá (Tamandua tetradactila), tacaca (Didelphis marsupislis), raposa (Dusicion vetulus), preá (Galea spixii). técnica de Soroaglutinação Microscópica segundo o número de amostras

\begin{tabular}{|c|c|c|c|c|c|c|c|}
\hline \multirow[t]{2}{*}{ Sorotipo reator } & \multicolumn{2}{|c|}{ Amostras reatoras } & \multicolumn{5}{|c|}{$\begin{array}{c}\text { Soroaglutinação microscópica } \\
\text { Títulos }\end{array}$} \\
\hline & № & $\%$ & 100 & 200 & 400 & 800 & 1.600 \\
\hline australis & 3 & 11,54 & 1 & 2 & -- & -- & -- \\
\hline bratislava & 4 & 15,38 & 1 & 3 & -- & -- & -- \\
\hline autumnalis & 11 & 42,31 & 4 & -- & 4 & 3 & -- \\
\hline butembo & 2 & 7,69 & 1 & 1 & -- & -- & -- \\
\hline grippotyphosa & 2 & 7,69 & 2 & -- & -- & -- & -- \\
\hline icterohaemorrhagiae & 2 & 7,69 & 2 & -- & -- & -- & -- \\
\hline wolffi & 1 & 3,85 & -- & -- & -- & 1 & -- \\
\hline andamana & 1 & 3,85 & -- & -- & -- & -- & 1 \\
\hline \multirow[t]{2}{*}{ TOTAL } & 26 & & 11 & 6 & 4 & 4 & 1 \\
\hline & & 100 & 42,31 & 23,08 & 15,38 & 15,38 & 3,85 \\
\hline
\end{tabular}

Tabela 2: Resultado dos exames de soro sangüíneo de cães de caça através da técnica de Soroaglutinação Microscópica segundo o número de amostras colhidas por cidades, amostras positivas e sorotipos. Patos-PB, 2002.

\begin{tabular}{|c|c|c|c|c|c|}
\hline \multirow[t]{2}{*}{ Cidade } & \multicolumn{2}{|c|}{$\begin{array}{c}\text { Amostras } \\
\text { colhidas }\end{array}$} & \multicolumn{2}{|c|}{$\begin{array}{l}\text { Amostras } \\
\text { positivas }\end{array}$} & \multirow[t]{2}{*}{ Sorotipos * } \\
\hline & no & $\%$ & № & $\%$ & \\
\hline Santa Luzia & 26 & 13,68 & --- & --- & --- \\
\hline Patos & 44 & 23,16 & 4 & 23,53 & $\begin{array}{c}\text { Aut.;But.; } \\
\text { Gri.; Ict. }\end{array}$ \\
\hline São José do Bonfim & 21 & 11,05 & 2 & 11,77 & Aut.; Gri.; Ict. \\
\hline Cubatí & 12 & 6,32 & 1 & 5,88 & Wol \\
\hline Lagoa & 11 & 5,79 & --- & -- & -- \\
\hline São Bentinho & 21 & 11,05 & 1 & 5,88 & Aut \\
\hline Catolé do Rocha & 09 & 4,74 & 2 & 11,77 & $\begin{array}{c}\text { Aut.; But.; } \\
\text { Gri }\end{array}$ \\
\hline Paulista & 10 & 5,26 & 1 & 5,88 & Aut \\
\hline Piancó & 12 & 6,32 & 1 & 5,88 & lct \\
\hline Itaporanga & 15 & 7,89 & 2 & 11,77 & $\begin{array}{c}\text { Aus.; Bra.; } \\
\text { Aut }\end{array}$ \\
\hline São José de Piranhas & 09 & 4,74 & 3 & 17,64 & $\begin{array}{c}\text { Aus.; Bra.; } \\
\text { Aut }\end{array}$ \\
\hline TOTAL & 190 & 100 & 17 & 100 & \\
\hline
\end{tabular}

*Aus. = australis; Bra. = bratislava; Aut. = autumnalis; But.= butembo; Gri. = grippotyphosa; Ict. = icterohaemorrhagiae; Wol. $=$ wolffi e And. = andamana 
Tabela 3: Resultados dos exames de soro sangüíneo de cães de caça segundo a faixa etária e a natureza dos resultados. Patos-PB, 2002

\begin{tabular}{|c|c|c|c|c|c|c|c|c|}
\hline \multirow{3}{*}{ Reator } & \multicolumn{6}{|c|}{ Idade } & \multicolumn{2}{|c|}{ Total } \\
\hline & \multicolumn{2}{|c|}{ Inferior a 2 anos } & \multicolumn{2}{|c|}{2 a 4 anos } & \multicolumn{2}{|c|}{ superior a 4 anos } & & \\
\hline & no & $\%$ & $\mathrm{n}^{\circ}$ & $\%$ & № & $\%$ & no & $\%$ \\
\hline$\overline{\text { Sim }}$ & 2 & 5,26 & 11 & 9,78 & 4 & 10,26 & 17 & 8,95 \\
\hline Não & 36 & 94,74 & 102 & 90,27 & 35 & 89,74 & 173 & 91,05 \\
\hline Total & 38 & 100 & 113 & 100 & 39 & 100 & 190 & 100 \\
\hline
\end{tabular}

Qui-quadrado $=0,8$

Tabela 4: Resultados dos exames de soro sanguíneo de cães de caça segundo número de vezes que caça ao mês e a natureza dos resultados. Patos-PB, 2002

\begin{tabular}{|c|c|c|c|c|c|c|c|c|}
\hline \multirow[t]{3}{*}{ Reator } & \multicolumn{6}{|c|}{ Número de vezes que caça ao mês } & \multirow{2}{*}{\multicolumn{2}{|c|}{ Total }} \\
\hline & \multicolumn{2}{|c|}{0 a 3} & \multicolumn{2}{|c|}{4 a 6} & \multicolumn{2}{|c|}{7 a 10} & & \\
\hline & no & $\%$ & no & $\%$ & № & $\%$ & no & $\%$ \\
\hline$\overline{\operatorname{Sim}}$ & 6 & 8,7 & 6 & 7,41 & 5 & 12,5 & 17 & 8,95 \\
\hline Não & 63 & 91,3 & 75 & 92,59 & 35 & 87,5 & 173 & 91,05 \\
\hline Total & 69 & 100 & 81 & 100 & 40 & 100 & 190 & 100 \\
\hline
\end{tabular}

Qui-quadrado $=0,86$

\section{Discussão}

A presente pesquisa, com cães de caça no semi-árido do Brasil, apresentou uma prevalência de $8,95 \%$, enquanto que trabalho realizado em cães domiciliados na zona rural do município de Pelotas-RS, apresentou 2,66\% (Jouglard et al., 1999). Alves et al. (2000) realizaram uma pesquisa com cães domiciliados no município de Patos-PB encontrando uma prevalência de $20 \%$. Outros inquéritos sorológicos realizados no Brasil, para leptospirose em cães, têm revelado prevalências muito variáveis, como: 25,38\% (Machado et al., 1999); 34,8\% (Avila et al., 1998); 18,14\% (Lilenbaum et al., 2000); 7,7\% (Reis et al., 1973), como também trabalho realizado na Austrália que encontrou $9,8 \%$ de positividade (Dickeson; Love, 1993). Essas diferentes prevalências, observadas em diferentes regiões do Brasil, como também em outros países, mostram que a ocorrência de leptospirose pode variar de acordo com a região, topografia, temperatura, precipitações pluviométricas, bem como demais fatores ambientais (Ávila et al., 1998).

Verificou-se que $85,26 \%$ dos cães de caça utilizados neste trabalho eram criados presos, sendo soltos por ocasião da prática da caça no meio rural, sendo que este ambiente é habitado por várias espécies de animais silvestres. Desta forma, os cães de caça circulando neste meio, ficaram expostos ao risco de contaminação por leptospiras ao entrarem em contato com águas contaminadas com a urina desses animais silvestres, visto que André-Fontain e Ganiere (1990) salientaram que, após a infecção, os animais tornamse fonte de disseminação de leptospiras através da urina e que animais domésticos e espécies silvestres como ouriços, corças, javalis, raposas, esquilos e mesmo sapos, já foram identificados como disseminadores de leptospiras. A urina eliminada por estes animais contamina o ambiente, particularmente rios e lagos, que se tornam vias de transmissão das leptospiras para o homem e animais. Adicionalmente, Santos et al. (2000) no semi-árido nordestino e Castro et al. (1961) em São Paulo, isolaram leptospiras de tecido renal de roedores silvestres.

Há uma variação quanto à distribuição dos sorotipos de leptospiras em diferentes estados brasileiros. Tomando-se como parâmetro os três principais sorotipos encontrados por cada autor, vê-se que no Rio Grande do Sul predominam canicola, icterohaemorrhagiae e copenhageni (Avila et al., 1998), canicola, grippotyphosa e pyrogenes (Machado et al., 1999) icterohaemorrhagiae, australis e copenhageni (Jouglard et al., 1999), sendo apenas este trabalho feito com cães da zona rural. $\mathrm{Na}$ Amazônia, Belo Horizonte, Rio de Janeiro e São Paulo, destacam-se icterohaemorrhagiae e canicola (Lilenbaum et al., 2000; Reis et al., 1973; Lilenbaum et al., 1997 e Yasuda et al., 1980) respectivamente. No Paraná foi verificada a prevalência dos sorotipos pyrogenes, autumnalis, e bratislava e bataviae (Rodrigues et al., 1997), enquanto no presente trabaIho houve prevalência dos sorotipos autumnalis, bratislava, australis, além de outros sorotipos como mostra a Tabela 2, concordando parcialmente com Alves et al. (2000) que citam a prevalência dos sorotipos autumnalis, butembo, grippotyphosa e australis em cães domiciliados no semi-árido nordestino. Na mesma região Alves et al. (2003) detectaram, em gatos, anticorpos contra os sorotipos autumnalis, pomona, bratislava e icterohaemorrhagiae, e Santos et al. (2000) encontraram anticorpos contra australis e butembo em roedores silvestres. Estes animais silvestres podem estar atuando, na região, como reservatórios destas leptospiras uma vez que os mesmos autores isolaram espiroquetas a partir do tecido renal. Além disso, André-Fontaine e Ganiere (1990) comentam que numa amostra limitada de 70 raposas, foram encontrados sorogrupos de leptospiras semelhantes aos achados em cães (icterohaemorrhagiae, autumnalis, pyrogenes e canicola).

Os sorovares de leptospiras mais importantes para os cães são: icterohaemorrhagiae, que também é o agente causal da doença de Weill no homem, e canicola (Hartman, 1986 apud Avila et al., 1998). Observa-se atualmente em humanos e em animais, a crescente introdução de outros sorotipos de Leptospira spp. causando doença clínica, como citam Pregnolatto et al. (1999) que encontraram o sorotipo autumnalis em humanos, e Kalin et al. (1999) que descreveram três casos de leptospirose em cães pelo sorotipo pomona, tendo ainda sido encontrado nesses animais anticorpos para os sorotipos grippotyphosa, bratislava e hardjo. Adicionalmente, outros autores têm citado casos de leptospirose canina por outros sorotipos como bratislava e grippotyphosa (Ribotta et al., 2000); Brown et al. (1996) que isolaram o sorotipo grippotyphosa de cães com leptospirose e Prescott et al. (2002) citam o sorotipo autumnalis como o maior envolvido com o ressurgimento da leptospirose canina em Ontário/Canadá, seguidos de bratislava, grippothiphosa e ponona. Os achados da presente pesquisa reforçam tais informações, já que encontramos prevalência de sorotipos diferentes dos tradicionalmente encontrados em cães, entretanto, Prescott et al. (2002) concluem que futuros trabalhos devem ser feitos para isolar, identificar e diferenciar os sorotipos envolvidos no ressurgimento da doença na sua região. 
No presente trabalho observou-se prevalência dos títulos 100 (42,31\%), 200 (23,08\%), 400 e 800 (15,38\%) e 1.600 (3,85\%). Outros trabalhos apresentam distribuição semelhante dos títulos (Machado et al., 1999 e Avila et al., 1998). Como os cães de caça utilizados neste estudo não eram vacinados contra leptospirose, os títulos encontrados indicam a possibilidade do contato com leptospiras e, como o período de leptospirúria pode ser longo nesta espécie, eles podem estar eliminando estes agentes com a urina, servindo de fonte de infecção para outros cães e/ou para os animais silvestres da região, e até para seus donos. A prevalência de títulos baixos, verificados nos cães de caça, deve-se a um quadro de infecção crônica ou assintomática, pois durante a colheita das amostras de sangue, os cães foram encontrados aparentemente sem alterações clínicas. No entanto, deve-se tomar muito cuidado na interpretação de títulos baixos nas reações positivas, pois segundo Farina (1968) apud Avila et al. (1998) títulos 100 ou 200 podem aparecer no início da doença, bem como tardiamente em alguns casos. Eentretanto, Santa Rosa (1970) apud Avila et al. (1998) afirma que um título 100 é suficiente para confirmar o diagnóstico. Em geral, um título simples alto (800 ou maior) é suficiente para um diagnóstico de leptospirose se a história clínica e laboratorial do paciente forem compatíveis (Wohl, 1996), ou quando há uma variação mínima de 4X no título de anticorpos entre amostras pareadas do mesmo paciente (Pregnolatto et al., 1999), sendo recomendado associar sorologia e testes para detectar a presença de leptospiras em tecidos ou fluidos do organismo (Kalin et al., 1999), para o diagnóstico definitivo da doença.

\section{Referências}

AGUIRRE, W.G.; SILVA, I. Isolamento in Argentina di um ceppo di leptospira apartenente al serotipo pyrogenis. Ann Inst Super Sanitá, v. 5, p. 1956. 1969.

ALVES, C.J.; ANDRADE, J.S.L.; VASCONCELLOS, S.A.; MORAIS, Z.M.; AZEVEDO,S.S.; SANTOS, F.A. Avaliação dos níveis de aglutininas anti-leptospira em cães no município de Patos-PB, Brasil. Rev. bras. Ci. Vet., v. 7, n. 1, p. 17-21, 2000.

ALVES, C.J.; VASCONCELLOS, S.A.; MORAIS, Z.M.; ANDRADE, J.S.L.; CLEMENTINO, I.J.; AZEVEDO,S.S.; SANTOS, F.A. Avaliação dos níveis de aglutininas anti-leptospira em gatos no município de Patos-PB. Clínica Veterinária, v. 8, n. 46, p. 48-54, 2003.

ANDRE-FONTAINE, G.; GANIERE, J.P. New topics on leptospirosis. Comp. Immun. Microbiol. infect. Dis. v. 13, n. 3, p. 163-168, 1990

AVILA, M.O.; FURTADO, L.R.I.; TEIXEIRA, M.M. et al. Aglutininas antileptospíricas em cães na área de influência do Centro de Controle de Zoonoses, Pelotas, RS, Brasil. Ciência Rural, Santa Maria, v. 28, n. 1, p. 107-110, 1998.

AZEVEDO, A.G.; SANTOS, J.S. Sobre a ocorrência de leptospirose no Rio de Janeiro, In:CONGRESSOBRASILEIRODEMEDICINA VETERINÁRIA, 3. ed., Porto Alegre, Anais... Porto Alegre, SOVERGS, p. 115-163. 1945.

BAUAB, A.R.; MATSUO, M.G.S.S.; BRANDÃO, M.M. Isolamento de leptospira em cães na cidade de São Paulo, Brasil. In: Anais... ENCONTRO NACIONAL EM LEPTOSPIROSE, 3., Rio de Janeiro, 157 p. 1993.

BROWN, C.A.; ROBERTS, A.W.; MILLER, M.A. et al. Leptospira interrogans serovar grippotyphosa infection in dogs. JAVMA, v. 209, n. 7, p. 1265-1267, 1996.

CASTRO, A. F. P.; SANTA ROSA, C. A.; TROISE, C. Preás (Cavia aperae azarae, LICH.) - (Rodentia: cavidae) como reservatório de Leptospira em São Paulo: isolamento de leptospira icterohaemorrhagiae. Arquivos do Instituto Biológico, São Paulo, v. 28 - art. 23, 1961.
Das 11 cidades onde foram colhidas as amostras, apenas duas não apresentaram animais positivos para leptospirose. Dos 17 cães de caça positivos para leptospirose apenas um era fêmea. Desse modo, esta pequena diferença de positividade entre machos e fêmeas não pode ser considerada significativa, pois $90,53 \%$ dos animais utilizados para esta pesquisa eram constituídos por machos, devido a poucos caçadores utilizarem fêmeas nas suas atividades de caça. Os quatro cães criados soltos, que reagiram positivamente para leptospira podem ter contraído a infecção tanto no ambiente silvestre, a partir do contato com animais portadores, ou em ambientes contaminados com a urina desses animais, uma vez que Santos et al. (2000) isolaram espiroquetas a partir de rins de roedores silvestres (preás) na Paraíba, os quais apresentavam também sorologia positiva para os sorotipos australis e butembo; como no ambiente urbano, pois, apesar da maioria dos cães de caça serem criados presos, tinham contato com outros cães e até com gatos, e trabalhos anteriores, na mesma região, com cães e gatos domiciliados mostraram que o sorotipo autumnalis foi o mais prevalente (Alves et al., 2000 e 2003).

\section{Conclusão}

De acordo com os resultados do presente trabalho, observou-se que cães de caça na Paraíba apresentaram aglutininas antileptospíricas, indicando que eles tiveram contato prévio com as leptospiras, seja no ambiente silvestre, seja no urbano.

CASTRO, A.F.P.; SANTA ROSA, C.A., TROISE, C. et al. Leptospirose canina em São Paulo: inquérito sorológico e isolamento da leptospira ictero. Arq Inst Biol, São Paulo, v. 23, p.199-205, 1962.

DICKESON, D.; LOVE, D.N.A. Sorological survey of dog, cats and horses in south-esstern Austrália for leptospiral antibodies. Astralian Veterinary Journal, v. 70, n. 10, p. 389-90, 1993.

FAINE. S. Guidelines for the control of leptospirosis. Geneva, World Health Organization, 171 p., 1982. (Who off set publicacion, 67).

GALTON, M.N.; SULZER, C.R.; SANTA ROSA, C.A.; FIELDDS, M.J. Apilication of a Microtecnhque to the Aglutination Test for Leptospiral Antibodies. Applied Microbiology, v. 13, p. 81-85. 1965.

GÍRIO, R.J.S. Abordagem clínica da leptospirose animal. In: Anais... ENCONTRONACIONAL EMLEPTOSPIROSE, 3. Rio de Janeiro. 157p. 1993.

GUIMARÃES, M.C.; CÔRTES, J.A.; VASCONCELLOS, S.A.; ITO, F.H. Epidemiologia e controle de leptospirose em bovinos. Papel do portador e seu controle terapêutico. Comunicações Científicas da Faculdade de Medicina Veterinária e Zootecnia da Universidade de São Paulo. n. 6/7, p. 21-34, 1982,1983.

HAGIWARA, M.K. Aspectos clínicos e epidemiológicos da leptospirose animal. In: Anais... ENCONTRO NACIONAL EM LEPTOSPIROSE, 3., Rio de Janeiro. 157 p. 1993.

JOUGLARD, S.D.D.;BROD, C.S.; FEHLBERG, M.F. et al. Prevalência da leptospirose canina, fatores de risco e sorovaes miss prevalentes no meio rural do Município de Pelotas, RS. In: CONGRESSO ESTADUALDE MEDICINA VETERINÁRIA, 14.,1999, Gramado-RS. Anais..., p. 102. 1999.

KOLOCHINE, E.; GORET, P.; BAUCHET, A. Enquete serologique sur la frequence en France des infections leptospirosiques canines. Bull Acad Vet Fr, v. 30, p. 423-426, 1957.

KALIN, M.; DEVAUX, C.; DiFRUSCIA, R.; LEMAY, S.; HIGGINS, R. Three cases of canine leptopiresis in Quebec. Can Vet J. v. 40, p. 187-191, 1999. 
LILENBAUM, W.; CAVALCANTE, M.F.H.; RIBEIRO, E.R.; DANIEL, C. Dosagem de uréia sanguínea em cães com leptospirose. R. bras. Méd. Vet., v. 19, n. 6, p. 233-237, 1997.

LILENBAUM, W.; RODRIGUES, F; BARBOSA, F. Aglutininas antileptospiras em caninos no município amazônico de Oriximiná-Pará, Brasil. R. bras. Ci. Vet., v.7, n. 3, p. 133-135, 2000.

MACHADO, R.R.; BROD, C.S.; CHAFFE, A.B.P. et al. Leptospirose canina na região sul do Rio Grande do Sul no ano de 1998. In: CONGRESSO ESTADUAL DE MEDICINA VETERINÁRIA, 14., 1999, Gramado-RS. Anais..., 1999. p. 103.

PREGNOLATTO, B.P.; RODRIGUES, P.; ARREAZA, A.L.V. et al. Estudo soroepidemiológico da leptospirose na Baixada Santista, São Paulo, Brasil. NewsLab. n. 31, 1999.

PRESCOTT, J.F.; McEWEN, B.; TAYLOR, J.; WOODS, J.P.; ABRAMSOGG, A.; WKCICJ, E. Resurgence of leptospirosis in dogs in Ontario: recent findings. Can. Vet. J., v. 43, n. 12, p. 955-961, 2002.

RODRIGUES, C. G.; VIEIRA, A. M.; PRETTO, L. G. et al. Sorotipos detectados através da prova de aglutinação microscópica em cães com suspeita de leptospirose. In: CONGRESSO ESTADUAL DE MEDICINA VETERINÁRIA, 13.,1997, Gramado-RS. Anais..., 1997.p. 173.
REIS, R.; RYU, E.; MOTTA, J.G.; WIEST, J.M. Pesquisa de aglutininas antileptospiras em cães através do teste da microaglutinação rápida. Arq. Esc. Vet. v. 25, n. 1, p. 15-22, 1973.

RIBOTTA, M.; FORTIN, M.; HIGGENS, R. Canine leptospirosis: serology. Can. Vet. J., v. 41, p. 494-495, 2000.

SANTOS, F.A.; ALVES, C.J.; AZEVEDO, S.S.; ANDRADE, J.S.L.; CLEMENTINO, I.J.; FREITAS, T.D. Isolamento de leptospiras patogênicas a partir do tecido renal de roedor silvestre (Gálea spixii spixii). In: ENCONTODE INICIAÇÃO CIENTÍFICA DA UFPB, 8., 2000, João Pessoa, Resumos... João Pessoa: Editora universitária/UFPB, 2000. p. 135.

TUNER, L. H. Leptospirosis I. Transactions of the Royal Society of Tropical Medicine and Hygiene, v. 61, p. 842-855, 1967.

VASCONCELLOS, S.A. O papel dos reservatórios na manutenção de leptospirose na natureza. Comunicações Científicas da Faculdade de Medicina Veterinária e Zootecnia da Universidade de São Paulo, v. 11, p. 17-24, 1987.

WOHL, J.S. Canine leptospirosis. The Copendium. v. 18, n. 11, p.12151225, 1986.

YASUDA, P.H.; SANTA ROSA, C.A.; YANAGUITA, R.M. Variação sazonal na prevalência de leptospirose em cães de rua da cidade de São Paulo, Brasil. Rev. Saúde públ., v. 14, p. 589-96, 1980. 